\title{
SILVAS EM TRÊS TEMPOS: EMULAÇÃO E ENGENHO EM Estácio, Poliziano, Quevedo
}

SILVAE IN THREE STEPS: EMULATION AND INGENUITY IN

Statius, Poliziano, Quevedo

Leni Ribeiro Leite

Universidade Federal do Espírito Santo

Vitória-ES

\begin{abstract}
This paper aims to examine the use of the term Silua to name a short poetic composition, of laudatory tone and spontaneous character, from Statius' five books to the learned encomia by Angelo Poliziano. Based on some considerations on the uses of the term in Antiquity, in Varro, Quintilian and Suetonius, we aim to discuss the characteristics of Statius' Siluae as reworked by Poliziano. Finally, the continuity and metamorphosis of the term in the poetic field in other vernacular languages is demonstrated through Quevedo's Silvas.
\end{abstract}

Keywords: Silvae, Statius, Angelo Poliziano, Quevedo.

\section{Resumen}

Este trabajo tiene por objetivo observar el uso del término Silva para nombrar una composición poética corta, de tono laudatorio y de carácter espontáneo, desde los cinco libros de Estácio hasta los encómitos eruditos de Angelo Poliziano. A partir de la consideración de algunos de sus empleos en la Antigüedad, en Varrón, Quintiliano y Suetonio, se pretende discutir las características de las Siluae de Estacio conforme recuperadas por Poliziano; finalmente, se apunta a la continuidad y metamorfosis del término en la producción poética en lenguas vernáculas, a través de las Silvas de Quevedo.

Palabras claves: Silvas, Estácio, Angelo Poliziano, Quevedo.

\section{Resumo}

Este trabalho tem por objetivo observar o uso do termo Silua para nomear uma composição poética curta, de tom laudatório e de caráter espontâneo, desde os cinco livros de Estácio até os encômios eruditos de Angelo Poliziano. A partir da consideração de alguns dos seus empregos na Antiguidade, em Varrão, Quintiliano e Suetônio, pretende-se discutir as características das Siluae de Estácio conforme recuperadas por Poliziano; por fim, aponta-se para a continuidade e metamorfose do termo na produçáo poética em línguas vernáculas, através das Silvas de Quevedo.

Palavras-chave: Silvas, Estácio, Angelo Poliziano, Quevedo. 
Retirado en la paz de estos desiertos con pocos, pero doctos libros juntos, vivo en conversación con los difuntos, y escucho con mis ojos a los muertos. (QUEVEDO, Desde la torre, c. 1637)

De Públio Papínio Estácio, poeta latino do primeiro século de nossa era, temos três obras: a épica Tebaida, a inacabada Aquileida e um conjunto de poemas de mais difícil definição. As Siluae, de Estácio, são uma coleção composta por trinta e dois poemas de curta e média extensão, normalmente categorizados como poesia de ocasião. Assim como outros autores do mesmo período, Estácio tem-se beneficiado de estudos que tendem a rever as posiçóes tradicionais da crítica histórica e literária em relação ao governo de Domiciano, por um lado, e à produção literária do período, por outro, levados a cabo em especial a partir da década de sessenta do século XX. ${ }^{1}$

Podem-se considerar duas obras como essenciais neste processo, do ponto de vista da crítica literária. Em 1965, o pesquisador alemão Hubert Cancik deu início a um novo capítulo na história da fortuna crítica de Estácio, em geral, e das Siluae, em particular, com uma monografia em que investiga as origens retóricas do que ele considera os dois principais obstáculos à apreciação moderna da obra, a saber, o estilo denso e elaborado (muitas vezes denominado maneirista, o que sempre causa estranhamentos de ordem teórica), e seu conteúdo encomiástico, considerado ao gosto moderno como bajulatório. Mais tarde, em 1983, Alex Hardie publicou um trabalho em que identificava as Siluae com o meio cultural grego da Baía de Nápoles; estas ideias, posteriormente desenvolvidas por Holford-Strevens (2000), McNelis (2007) e Newlands (2012), mostraram-se cruciais para a crítica de Estácio. Em resumo, a prática da epidêixis e o conhecimento aprofundado de literatura grega, inclusive para além da canônica, fazem de Estácio, como demonstra Holford-Strevens (2000, p. 53), um poeta latino cujos escritos devem ser diligentemente lidos "em suas fontes gregas, suas alusóes gregas e suas intertextualidades gregas".

Por outro lado, ainda que a influência grega possa ser considerada uma das razóes para o discurso sofisticado de Estácio, ela não é suficiente para explicar as Siluae, em sua própria existência como obra sui generis ou simplesmente único representante de um estilo de poesia estabelecido no período. O próprio título talvez seja o símbolo maior deste debate. Como é característica da poesia ricamente alusiva do mundo antigo, o título da obra

1 Citem-se, apenas como exemplo, Waters (1964), Pleket (1961), Jones (1992), Southern (2009) e vários capítulos do recente Companion to the Flavian Age of Imperial Rome (ZISSOS, 2016). 
de Estácio tem, é claro, múltiplas associações, como discute Wray (2007). Este título, se entendido simplesmente como floresta ou bosque, liga a coleção de Estácio à poesia helenística, em especial às coleçóes de epigramas, que costumavam ser nomeadas por termos sugerindo natureza, tais como flores e campinas; era também chamada silua a "matéria", no sentido de texto escrito rapidamente, sem revisão, quase ainda um rascunho, como em Quintiliano (Inst. X.3.17), ou mesmo em Cícero (Orat. III.12), que chama de silua o material cru que o orador vai utilizar. Esta é uma das interpretações possíveis para o título: matéria confusa e mal elaborada, como que um rascunho de algo a ser mais tarde polido. Newlands (2002, p. 36-38) sugere ainda que este título anuncia a conexão da obra com a nova e politizada versão da poesia pastoral: no início da Écloga 4, Vergílio usa a palavra siluae para designar sua composição, ${ }^{2}$ ao programaticamente anunciar que ele deixará os bosques humildes, onde até entấo caminharam os pastores, para falar de paulo maiora, coisas um pouco mais elevadas. Vergílio, nesse momento, introduz o panegírico nos bosques pastoris, e ter escolhido o nome Siluae insere Estácio em uma genealogia poética que ampliou as possibilidades da poesia teocritiana ao introduzir figuras públicas e temas nacionais às Éclogas. Estácio dá continuidade a essa ordem nas Siluae, aprofundando as suas implicaçóes, concentrando-se sobre questóes sociais e políticas suas contemporâneas. Como diz Tanner (1986) "the proper commentary on this choice of title for the whole collection may therefore be Vergil, Ecloga 4, 1-3"3.

Logo, quanto ao título dos poemas, em uma opiniáo que pode ser considerada corroborada pelo autor, a escolha do substantivo Siluae indicaria apenas que a obra é composta por versos triviais, sem muita elaboração, como parece querer dizer o próprio Estácio no prefácio ao livro I, quando caracteriza os poemas da coleção como composiçôes "qui mihi subito calore et quadam festinandi voluptate fluxerunt (...) nullum enim exillis biduo longius tractum, quaedam et in singulis diebus effusa" (Stat. Silv. I.praef). Por outro lado, silua pode significar um novo tipo de poesia, que, respondendo ao chamado de Vergílio, estabelece um estilo próprio para o período flaviano, uma poética do império, como a designa Carole Newlands (2002), em que a dialética entre o campo e a cidade, presente de forma aguda em Vergílio, se perpetua nos contrastes entre urbs e uilla, engajamento ou afastamento da vida política. Para além disso, em sua representação de uma cidade que é uma alternativa

2 Si canimus siluas, siluae sint consule dignae (VERG. Ecl. IV.3). Se cantamos florestas, que sejam florestas dignas de um cônsul. Todas as traduçóes, exceto quando informado o contrário, são de nossa autoria.

$3 \mathrm{O}$ comentário apropriado a esta escolha de título para a coleção completa pode, portanto, ser Vergílio, Écloga 4, 1-3.

4 Que para mim fluíram no calor do momento e com um certo prazer na pressa (...) de fato, nenhum deles levou mais do que dois dias para compor, alguns foram feitos em um só dia. 
à vida imperial, Estácio também toca nas relaçóes que Ovídio representa nas Tristia, ${ }^{5}$ invertendo-as.

Junta-se, portanto, ao princípio da rapidez como característica da Silua justamente este diálogo ambíguo com a tradição, que ao mesmo tempo a confirma e a refuta, transmutando elementos tradicionais em algo novo, jamais ouvido, mas que soa como algo já conhecido. $\mathrm{O}$ diálogo permanente dessa força, mantenedora mas transformadora, é o que resume a própria questão do gênero das Siluae. Como vimos, o título não as define; quanto ao conteúdo, os poemas destes cinco livros não podem ser classificados em conjunto como pertencentes ao gênero elegíaco, lírico, epigramático ou qualquer outro dos gêneros tradicionais da poesia latina. Não é difícil classificar alguns dos poemas isoladamente, seja dentro dos gêneros tradicionais, seja dentro de gêneros retóricos - a identificação das Siluae com o gênero epidítico é já tradicional, como aponta Hardie (1983). O conjunto, porém, desafia a classificação.

Isso não impediu, no entanto, seu sucesso, e muitos imitadores e emuladores surgiram ainda na Antiguidade, como Ausônio, Ambrósio e Sidônio Apolinário entre outros que se dedicaram à escrita de Siluae, com as seguintes características definidoras: a) poemas de ocasião; b) temática variada sem ser, porém, satírica ou baixa; c) próprios ao elogio; d) com tons biográficos e de improvisação, ficcionais ou não; e) profundamente eruditos, no diálogo com a tradiçáo literária precedente. Essa estética do encômio e da êcfrase, que celebra a variedade do mundo e os acontecimentos da vida, foi bastante popular nos fins da Antiguidade e na Idade Média, por alguma razão não através de Estácio, mas de seus sucessores. Estácio não era, sem dúvida, um desconhecido; se hoje ele é um poeta que precisa ser apresentado e reapresentado aos leitores do século XXI, isso não era verdade no alvorecer da Idade Moderna: leitores, de Dante e Petrarca a Shakespeare e Milton, liam Estácio junto a Vergílio e Ovídio, mas primariamente como um poeta épico. A boa fortuna de sua épica é bem atestada, e Estácio era a principal fonte para a matéria de Tebas durante o medievo. Como exemplo e testemunho de sua fama, citem-se os versos de Justus Lipsius, assíduo comentador de Estácio no Renascimento (CLOGAN, 1988):

Eccum Papinium, benigne Lector.

Quis hic Papinius? Poeta magnus,

Vel dicam potius poeta summus;

Certe proximus est poeta summo,

Quod fateatur ipse Livor. ${ }^{6}$

(Iustus Lipsius, Epigrammata ad Bernartium)

5 As relaçôes entre Ovídio e Estácio são mais bem exploradas por Laguna-Mariscal (1994).

6 Eis Papínio, benigno leitor. / Quem é este Papínio? Um grande poeta, / ou, direi melhor, o maior poeta;/ certamente um poeta próximo ao melhor, / como confessa a própria Inveja. 
No entanto, da mesma maneira como ocorreu com vários autores clássicos, como Cícero, um novo Estácio foi descoberto no Renascimento. Conforme afirma Mengelkoch (2010, p. 2), a redescoberta das Siluae, em 1418, por Poggio Bracciolini, renovou o interesse no tipo de herança poética, ligada ao mesmo tempo à tradição romana e à grega, que Estácio representava. Assim, suas obras tiveram nada menos que cento e oitenta e oito ediçóes entre 1472 e 1700 .

Foi outro o italiano, porém, responsável pela promoção da obra de Estácio e por sua popularidade: Angelo Poliziano ${ }^{7}$, que não apenas escreveu, a partir de 1475, um longo e douto comentário (não publicado à época) sobre as Siluae, mas escolheu Estácio e Quintiliano como tema de sua palestra introdutória em seu primeiro ano acadêmico como professor no Studio Fiorentino, a Oratio Super Fabio Quintiliano et Statii Sylvis, do ano de 1480. Esse interesse especial de Poliziano por Estácio, e pelas Siluae em particular, está em relação com toda a restante obra do autor. De acordo com Poliziano, Estácio foi, antes de tudo, igual a e sucessor de Vergílio, com tudo o que isso significa, e não apenas um imitador.

Um índice desse posicionamento pode ser visualizado na famosa troca de cartas entre Poliziano e Cortésio (McLAUGHLIN, 1996) acerca da imitação, e que ocorre justamente durante este período. Nela podemos ver que Poliziano, que escreveu também uma obra denominada Siluae, justifica não só a escolha de Estácio como tema e das Siluae como tópico de aulas, mas também como objeto de imitação. Negando o ciceronianismo promovido por Cortesio, rejeitando a imitação servil (de um macaco, como diz Poliziano ${ }^{8}$ ) e optando, inclusive com base em exemplos clássicos, como Sêneca, pelo uso de outros modelos literários, Poliziano foi um defensor de que se buscasse, para a formação do intelectual, multa et remota lectio ${ }^{9}$ (Nutricia, praef). Os assuntos que Poliziano escolheu como tema de suas aulas, de 1480 a 1494, ano de sua morte, revelam o caminho de seu pensamento, contrariando as tendências do momento: enquanto Cortésio e Cristoforo Landino defendiam Cícero como pedra fundamental da latinidade, Poliziano ensinava sobre Quintiliano; em vez das Metamorfoses, seus cursos sobre Ovídio versaram sobre as Heroides e os Fastos; e as Siluae foram também tópico de um curso. Na já citada oração sobre Quintiliano e Estácio, Poliziano adianta as críticas que sua escolha

\footnotetext{
7 Angelo Poliziano, latinizado Angelus Politianus, viveu entre 1454 e 1494, foi protegido da família Medici, e escreveu, além de muitas obras em latim, grego e toscano, o Commentarius de Statii Sylvis (1475), a Oratio Super Fabio Quintiliano et Statii Sylvis (1480) e uma coleção de Siluae (1482-1486) de sua própria autoria.

8 "Mihi vero longe honestior tauri facies aut item leonis quam simiae videtur" (Poliziano, Epistula I.1). Para mim a face de um touro ou de um leáo parece muito mais honesta do que a de um macaco. (DELLANEVA, 2007, p. 2)
}

9 Lição variada e antiga. 
incitaria, e confronta-as defendendo a superioridade dos novos modelos por ele escolhidos, contrastando Quintiliano com Cícero e Estácio com Vergílio (LOONEY, 1996, p. 43). Ele chama atenção para sua escolha consciente de um novo caminho - Novas tamen quasique intactas vias ingrediamur, veteres tritasque relinquamus ${ }^{\mathbf{1 0}}$ (Nutricia, 870) -, e é cuidadoso em afirmar que não rejeita Cícero em favor de Quintiliano; de fato, elogia Quintiliano, usando uma citação ciceroniana - inusitatas vias indagamus ${ }^{11}$ (Cic. Or. 3.11).

A visão pluralista da tradição literária, defendida por Poliziano em suas cartas e em sua oração, está presente, como já demonstrado por outros ( $c f$. MENGELKOCH, 2010), em sua própria produção poética: no Orfeu, nas Rime ao estilo de Petrarca, nos muitos epigramas latinos e gregos que ecoam Vergílio, Ovídio, Catulo, Tibulo, Propércio e, claro, Estácio. No entanto, ao se folhear o índice já se percebe que as Siluae de Poliziano não são como as de Estácio, nem no número nem na extensão.

As Siluae, de Estácio, são devedoras do epigrama: a brevidade, a variedade métrica, e principalmente os seus muitos temas, suas representaçóes da vida social, dos valores e das atitudes são facilmente conectados e conectáveis, como demonstra a série de textos críticos que traçam paralelos entre a obra de Estácio e a de Marcial nos últimos cinquenta anos (WHITE, 1974; 1975; NAUTA, 2002; GARTHWAITE, 1993; DOMINIK, 2016, entre outros). Surpreendentemente, porém, os poemas deste tipo escritos por Poliziano não estão recolhidos em suas Siluae, mesmo que ele use, no prefácio de sua obra Miscellania, de 1489, o termo silua com este sentido. As Siluae de Poliziano - se excluírmos a Sylva in scabiem, uma obra da juventude, problemática em sua datação e definição - são quatro: Manto, cujo tema é Vergílio, escrita em 373 versos; Rusticus, sobre Hesíodo, com 569 versos; Ambra, que versa sobre Homero, em 625 versos; e a maior e mais ampla, Nutricia, sobre a arte poética e os poetas, em 790 versos. Todas elas são prolusiones, normalmente prefácios em prosa, aqui em hexâmetros datílicos; Manto tem ainda um exórdio em dísticos elegíacos.

As Siluae de Poliziano têm como tema que as corta transversalmente a mesma imitatio que é tema de suas cartas: questôes de emulação, herança e rivalidade. O diálogo entre Estácio e sua tradição, em termos de mutabilidade e novidade, em especial em relação a Vergílio, Hesíodo e Homero, estabelece termos com os quais Poliziano pode lidar para expressar a sua própria posição em relação à tradição clássica. A ordem mesma dos poemas, seguindo o pensamento de Poliziano, caminha para trás no tempo, até os princípios da poesia, incorporando a literatura grega e romana, promovendo pluralismo em vez de purismo.

10 Caminhos novos, porém, e como que intactos persigamos, abandonemos os velhos e repisados.

11 Procuramos os caminhos desusados. 
Daquelas características elencadas por nós como sendo pertencentes às Siluas de Estácio e de outras posteriores, Poliziano escolhe duas como principais: a trama de erudição e a feição epidítica. Temos, portanto, poemas que são encômios literários eruditos, que não só elogiam autores antigos, mas ao mesmo tempo mostram pelo exemplo como se apropriar deles e retrabalhálos. Epidíticos, por certo, mas também didáticos - eles são poemas que se apresentam como um problema particular, segundo Simon (1984, p. 78): ao decidir falar de poesia pela poesia, Poliziano usa de uma dicção própria que busca a uariatio, expultrix fastidiae, ${ }^{12}$ como ele mesmo diz ainda no prefácio da Miscellania, que atende ao mesmo tempo à sua aspiração poética e à sua preocupação didática.

Como ainda Simon (1984, p. 78) já demonstrou, os poemas epidíticodidáticos de Poliziano seguem a moldura retórica esperada de uma praelusio em prosa, isto é, uma laus (elogio) do autor tema do curso, seguida de uma cohortatio (exortaçáa) aos alunos, mas sob forma poética. Se tomarmos como exemplo a primeira e menor Silua, Manto, encontraremos um exórdio, correspondente à fábula que abre o poema, em que uma paisagem carregada de referências à poesia antiga (a nau Argo, o centauro Quíron, Aquiles, Hércules, Orfeu, os pinheiros do monte Pélion, entre outros conhecidos dos leitores de literatura antiga) anuncia o tema do poema.

A abertura de Manto não é apenas uma referência mitológica ao estilo das Siluae - ela é especialmente estaciana, ao trazer um jovem Aquiles aos cuidados de Quíron que toma a lira para cantar. Os leitores de Poliziano reconheceriam imediatamente a cena como parte da Aquileida, transportandose ao mundo de Estácio; e, quando Poliziano diz Me quoque nunc magni nomen celebrare Maronis, ${ }^{13}$ veriam que ele se propunha, ali e então, como novo Estácio, segundo apenas em relação a Vergílio, e seu maior cultor.

Na parte seguinte, correspondente à narratio, expóe-se o tema do poema, o nascimento de Vergílio, com participação da deusa Nêmesis. Nesta parte, encontram-se, como na seguinte, marcadores do ritmo do discurso, comuns na retórica - perguntas, exclamaçóes, apóstrofes. Dentre elas, destacamos uma representação bastante eloquente de como se constroem as Siluae de Poliziano, apropriando-se da imagem da floresta - silua - já usada por Vergílio, como dissemos, na Écloga IV.

Unde ego tantarum repetam primordia laudum?

Aut qua fine sequar? Facit ingens copia rerum

incertum. Sic frondifera lignator in Ida

stat dubius, vastae quae primum robora silvae

12 Variedade, que expulsa o tédio.

13 Também a mim agora cabe celebrar o nome do grande Marão. 
vulneret: hinc patulam procero stipite fagum,

hic videt annosam sua pandere bracchia quercum

illic succinctas caput exsertare cupressos

metiturque oculis Phrigiae nemora alta parentis. ${ }^{14}$

(POLIZIANO, Manto, 39-46)

Seguem-se a confirmação e refutação, em que cada obra de Vergílio é comentada e poeticamente imitada. Por fim, a peroração é marcada pela elevação de tom. Seria muito longo demonstrar, mas Poliziano faz, durante todo o poema, a pedagogia do exemplo: ou seja, ele demonstra, pelo poema, como emular o autor, como se apropriar de temas e modificá-los, dando a eles forma nova; como reutilizar o vocabulário do autor; como reintegrar um trecho, às vezes um hemistíquio inteiro a um novo contexto. No trecho reproduzido acima, como exemplo, um leitor de Vergílio reconheceria alguns termos como ecos da primeira Écloga: silua, patula, fagus, quercus.

Esse gosto pela uariatio pode ser o que levou a crítica a chamar Poliziano de maneirista, se entendemos maneirismo não como decadência, mas como um certo tipo de sensibilidade aventureira e incisiva, ligada aos conceitos de ingenium (o engenho poético) e iudicium (a escolha dos bons modelos). As Siluae de Estácio e de Poliziano são textos metapoéticos que continuamente desafiam os leitores a reconhecer a sua "pilhagem poética" (MENGELKOCH, 2010, p. 99), reformatando várias obras anteriores. Esse conceito é mais claro na última Silua da coleção, a Nutricia.

Diferentemente das anteriores, a Nutricia não apresenta um só poeta ou um só tema: propóe-se a narrar a história da transmissão da poesia e apresentar a lista de poetas, famosos ou não. Novamente temos uma fábula no início, dedicada à Poesia como divindade, que cura os homens de sua selvageria e ignorância, pelo bem da humanidade. Na narrativa que se segue, Poliziano apresenta uma história da poesia em que os romanos sáo profundamente devedores dos gregos que lhe precederam, de diversas maneiras. Essa observação de uma poesia que é sempre um eterno refazer, em que cada poeta é devedor, continuador e transformador do que lhe precede, parece ser uma ampla defesa, desta vez poética, do mesmo processo que ele apresentou em sua oratio, já mencionada, em que se bebe de várias fontes, "pilhando" o de melhor de cada uma e recriando a poesia.

As Siluas de Poliziano dialogam de perto com Estácio - porém, no panorama dos séculos que se seguiram, ficaram como uma obra das menos

\footnotetext{
14 De onde eu começarei a cantar seus louvores? / Ou onde terminarei? A abundância me faz incerto. / Assim também o lenhador fica de pé sobre o frondífero monte Ida, / em dúvida sobre quais troncos da vasta floresta /ele primeiro golpeará: para cá ele vê uma larga faia com seu tronco erguido, / aqui ele vê um carvalho idoso estendendo seus ramos, / lá os curtos ciprestes esticam a cabeça, / e mede com os olhos os altos bosques da mãe Frígia.
} 
comuns dentre as demais que também se autodenominaram Siluae. Os poetas que se seguiram parecem ter preferido outras características das propostas para o gênero, e a silva tornou-se popular sob formas diversas. Como afirmam Kallendorf e Kallendorf (2000, p.144), a silva estava no próprio coração da cena literária espanhola dos séculos XVI e XVII, por exemplo. No entanto, a silva espanhola difere muito daquela de que viemos falando. A obra de Estácio não foi traduzida para o espanhol antes do ano de 1705, mas o termo silva aparece nos títulos de diversas obras espanholas do XVI: Silva de varia lección, de Pedro de Mexía (1542); Silva de romances (1550); Silva curiosa, de Julian de Medrano (1583). Nessas obras, porém, a palavra silva parece significar simplesmente coleção, compilação, agrupamento de coisas diversas. Um pouco mais tarde, o termo parece se estabilizar com o sentido de variedade métrica, muitas vezes um poema que combinava hendecassílabos e heptassílabos. A partir de 1605, praticamente só há Silvas - e há várias de muitos autores com a variedade métrica. A figura principal no estabelecimento deste gênero parece ter sido Luis de Góngora, cujas Soledades, escritas sob a forma de silvas métricas, começaram a circular em 1613 e, como mostra a grande quantidade de impressões, foram muitíssimo populares. Houve, porém, uma figura, tão popular quanto Góngora, que optou pela manutenção de uma silva clássica, aos moldes de Poliziano e Estácio.

As primeiras silvas de Francisco de Quevedo são vinte e uma silvas métricas; seguem-se logo, porém, outros poemas, também denominados silvas, em metros diversos. A palavra silva parece estar aí sendo usada com o sentido anterior, de uariatio, de flexibilidade, de uma forma que acomodaria uma miscelânea de poemas ocasionais, em gêneros literários e retóricos variados.

A predominância da silva métrica, ao gosto de Góngora e seus aliados, não impediu Quevedo de "conscientemente aliar-se a Estácio” (KALLENDORF; KALLENDORF, 2000, p. 148). Os autores dizem "conscientemente" porque sabemos que Quevedo esteve comprovadamente envolvido com as Siluas de Estácio por mais de trinta e cinco anos. Se antes pairavam dúvidas sobre o acesso do autor à obra, elas já não mais existem: desde o ano 2000, sabe-se que um exemplar da obra completa de Estácio, publicada em 1502 e atualmente na biblioteca de Princeton, traz a assinatura e muitas anotaçóes da mão de Quevedo, que certamente sabia latim e portanto conhecia a obra em primeira mão (KALLENDORF; KALLENDORF, 2000, p. 131).

Ainda pela sua biblioteca, pode-se afirmar que Quevedo não apenas conhecia, mas valorizava as obras dos autores canônicos da Literatura Latina; os reflexos desse conhecimento também se encontram espalhados por sua obra: o episódio de Dido, na Eneida, aparece em sua Imitación de Virgilio, para citarmos um caso. Essa relação não se limitava, porém, apenas aos grandes nomes, como Vergílio, Horácio, Ovídio: o estilo de Quevedo guarda traços do já citado "maneirismo" estaciano e de outros autores do período imperial. 
Dos trinta e seis poemas em metro variados, compostos entre 1603 e 1625, que Quevedo chamou silvas, nove podem ser diretamente vinculadas, no todo ou em parte, a uma silva específica de Estácio. Como exemplo, citemos uma:

¿Con qué culpa tan grave,

Sueño blando y süave, pude en largo destierro merecerte que se aparte de mí tu olvido manso? Pues no te busco yo por ser descanso, sino por muda imagen de la muerte.

(...)

Con pies torpes al punto, ciega y fría,

Cayó de las estrellas blandamente

La noche, tras las pardas sombras mudas, Que el sueño persuadieron a la gente.

Escondieron las galas a los prados

Y quedaron desnudas

Estas laderas y sus peñas solas:

Duermen ya entre sus montes recostados

Los mares y las olas.

Que blandos hallan en los cerros duros.

Los arroyuelos puros

Se adormecen al son del llanto mío,

$\mathrm{Y}$ a su modo también se duerme el río. ${ }^{15}$

(Quevedo, Al Sueño)

Crimine quo merui, iuvenis placidissime divum, quove errore miser, donis ut solus egerem, Somne, tuis? tacet omne pecus volucresque feraeque et simulant fessos curvata cacumina somnos, nec trucibus fluviis idem sonus; occidit horror aequoris, et terris maria adclinata quiescunt. ${ }^{16}$ (...)

(Stat. Silv. V.4)

15 Com que culpa tão grave / Sono brando e suave/ pude em tamanho exílio merecer / que se afastasse de mim teu esquecimento manso/ Pois não te busco eu por ser descanso / mas sim muda imagem da morte (...) Com pés toscos prontamente, cega e fria / caiu das estrelas suavemente / a noite, após as pardas sombras mudas, / que o sonho incitaram nas gentes. / esconderam os ornamentos (os adornos) dos prados / e ficaram desnudas / estas ladeiras e suas penhas sós; / dormem já entre seus montes recostados / os mares e as ondas. / Se com algum sotaque / ofendem os ouvidos, / é que entre sonhos dão ao céu queixas / do rígido leito e duro acolhimento, / que suaves encontram nos cerros duros. / Os riozinhos puros / adormecem ao som do meu pranto / E a seu modo também dorme o rio.

16 Por que crime mereci, jovem Sono, mais gentil dos deuses,

ou por que erro, que só eu, pobre de mim, carecesse de teus dons?

Todo o rebanho está em silêncio, e os pássaros e as feras,

e as copas curvadas simulam sonos cansados,

e os rios selvagens diminuem seu som; morre o tremor

das águas, e aquietam-se os mares, reclinados sobre os litorais. 
As semelhanças são evidentes, na menção a um erro ou crime do eu poético, que faria com que o sono o punisse; na personificação do sono, nas imagens de silêncio e tranquilidade com elementos da natureza. Ao tomar como modelo de suas silvas as de Estácio, Quevedo opta por dar continuidade a uma longa tradiçâo de poesia que prima por uma abordagem que chamaríamos humanística, cuja palavra de ordem é a uariatio, com busca por fontes diversas e que se complementem em um jogo poético inovador. Esta tradição parece ter tido como forma poética eleita e privilegiada a silva, que, já a partir de Estácio, previa como características a variedade métrica e temática, a dicção pessoal e simples e, principalmente, uma postura específica de erudição literária e referências a outras obras, como buscamos demonstrar.

\section{Referências bibliográficas}

CANCIK, Hubert. Untersuchungen zur lyrischen des P. Papinius Statius. Hildesheim: Georg Olms, 1965.

CLOGAN, Paul M. The Renaissance Comentators on Statius. In: INTERNATIONAL CONGRESS OF NEO-LATIN STUDIES, 7, 1988, Toronto. Acta Conventus Neo-LatiniTorontonensis: proceedings of the seventh International Congress of NeoLatin Studies. Toronto, Center for the Medieval and Early Renaissance Studies, 1991, p.273-280.

COLEMAN, Kathleen M. Statius Silvae IV. Oxford: Oxford University, 1988.

DELLANEVA, Joann. Ciceronian controversies. Cambridge, Mass.; London: Harvard University, 2007.

DOMINIK, William J. Epigram and Occasional Poetry: Social Life and Values in Martial's Epigrams and Statius' Silvae. In: ZISSOS, Andrew. A Companion to the Flavian Age of Imperial Rome. Malden, MA: John Wiley \& Sons, 2016. p. 412-33.

GARTHWAITE, John. The Panegyrics of Domitian in Martial Book 9. Ramus 22, 1993, p. 79-102.

HARDIE, Alex. Statius and the Silvae: poets, patrons and epideixis in the GraecoRoman world. Liverpool: David Brown, 1983.

HOLFORD-STREVENS, Leofranc. In search of Poplios Papinios Statios. Hermathena, 168, 2000, p.39-54.

KALLENDORF, Hilaire; KALLENDORF, Craig. Conversations with the Dead: Quevedo and Statius, Annotation and Imitation. Journal of the Warburg and Courtauld Institutes, Vol. 63, p. 131-168, 2000. 
JONES, Brian W. The Emperor Domitian. London: Routledge, 1992.

LAGUNA-MARISCAL, Gabriel. Statius' Silvae 3.5.44-49 and the genre of Ovid's Heroides. Rheinisches Museum fürPhilologie, NeueFolge, 137. Bd., H. 3/4, 1994, p. 352-357.

LOONEY, Dennis. Compromising the Classics: Romance Epic Narrative in the Italian Renaissance. Detroit: Wayne State University, 1996.

MCLAUGHLIN, Martin L. The Dispute between Poliziano and Cortesi. In: MCLAUGHLIN, Martin L. Literary Imitation in the Italian Renaissance. Oxford: Oxford University, 1996.

MCNELIS, Charles. Looking at the forest? The Silvae and Roman Studies: afterword. Arethusa, 40, 2, Spring, 2007, p. 279-287.

MENGELKOCH, Dustin Larry. Papinian mutability: Statius and early modernity. Tese de doutorado. North Carolina at Chapel Hill. Department of English and Comparative Literature, 2010.

NAUTA, Ruurd. Poetry for patrons: literary communication in the age of Domician. Leiden: Brill, 2002.

NEWLANDS, Carole. Statius, poet between Rome and Naples. London: Bristol Classical, 2012.

NEWLANDS, Carole. Statius and the Poetics of Empire. Cambridge: Cambridge, 2002.

PLEKET, H.W. Domitian, the Senate and the Provinces. Mnemosyne, n.14, 1961, p. 296-315.

POLIZIANO, Angelo. Silvae. Ed. and trans. Charles Fantazzi. Cambridge, Massachussetts: Harvard University, 2004.

SOUTHERN, Pat. Domitian: Tragic Tyrant. London; New York: Routledge, 2009.

STATIUS. Silvae . Ed. D.R. Shackleton Bailey. Cambridge, Massachussets: Harvard University, 2003.

TANNER, R. G. Epic Tradition and Epigram in Statius ANRW, II.32.5, 1986, p. 3020-3046.

WATERS, K. H. The Character of Domitian. Phoenix, n.18, 1964. p. 49-77.

WHITE, Peter. Presentation and Dedication of the Silvae and Epigrams. JRS, 64: p. $40-61,1974$.

WHITE, Peter. The Friends of Martial, Statius, Pliny, and the Dispersal of Patronage. HSCP, 79, p. 265-300, 1975. 
WRAY, David. Wood: Statius' Silvae and the Poetics of Genius. Arethusa, v. 40, n.2, Spring 2007, p. 127-143.

ZISSOS, Andrew (ed.). A Companion to the Flavian Age of Imperial Rome . Malden/ MA: Wiley-Blackwell, 2016.

Leni Ribeiro Leite. Professora de Língua e Literatura Latinas na Universidade Federal do Espírito Santo (UFES). Doutora em Letras Clássicas pela UFRJ, e autora, entre outros, de Marcial e o Livro (Edufes, 2011) e Épica II: Ovídio, Lucano, Estácio (Unicamp, 2016). Atua principalmente com Ensino de Latim, Literatura Latina do Império e Recepção dos Clássicos.

E-mail: leni.ribeiro@gmail.com 